\title{
AVALIAÇÃO DA PERCEPÇÃO DE INDICADORES DE QUALIDADE DE VIDA NO TRABALHO EM UM ABATEDOURO DE FRANGOS
}

\section{PERCEPTION ASSESSMENT OF QUALITY OF WORK LIFE INDICATORS IN A CHICKEN SLAUGHTERHOUSE}

\author{
Fabiano Takeda* E-mail: takeda.f@bol.com.br \\ Lizandra Garcia Lupi Vergara* E-mail: I.vergara@ufsc.br \\ Antônio Renato Pereira Moro* E-mail: renato.moro@ufsc.br \\ *Universidade Federal de Santa Catarina (UFSC), Florianópolis, SC.
}

Resumo: Considerando os altos índices de produção e exportação de produtos de origem animal no Brasil, manter níveis de qualidade de vida no trabalho (QVT) tornou-se essencial para as empresas se manterem competitivas. Este estudo teve como objetivo avaliar a percepção dos supervisores e gerentes de um abatedouro de frangos em relação à qualidade de vida no trabalho de sua equipe para verificar se as condições percebidas pelos entrevistados atendem os requisitos mínimos de QVT. O método utilizado para levantamento foi um questionário estruturado com 11 perguntas que foram realizadas na forma de entrevista. Para análise dos dados utilizou-se a ferramenta de análise de conteúdo proposto por Bardin (2011) e o questionário adaptado do modelo de QVT proposto por Walton (1973). O estudo limitou-se na aplicação de entrevistas em apenas funcionários do cargo de gestão de equipes. Os resultados da pesquisa apontam que em geral a percepção dos entrevistados é que a empresa atende as condições de QVT conforme modelo utilizado, evidenciando-se fatores positivos e negativos a serem analisados pela empresa, possibilitando mensurar as necessidades da empresa no nível gerencial que contribuem na QVT dos funcionários.

Palavras-chave: Qualidade de vida. Abatedouro. Saúde do trabalhador.

Abstract: Considering the high level of production and export of animal products in Brazil, maintaining quality of work life (QWL) has become essential for companies to remain competitive. This study aimed to evaluate the perception of supervisors and managers of a broiler slaughterhouse in relation to quality of work life of their team to verify if the conditions perceived by the interviewed meet the minimum requirements of QWL. The method used for survey was a structured questionnaire with 11 questions that were performed in the form of interviews. The data analysis tool proposed by Bardin (2011) and the questionnaire adapted from the QWL model proposed by Walton (1973) were used to analyze the data. The study was limited in the application of interviews in only personnel of the position of management of teams. The results of the research indicate that in general the interviewees' perception is that the company meets the QWL conditions according to the model used, evidencing positive and negative factors to be analyzed by the company, making it possible to measure the company's needs at the managerial level that contribute to the QWL of employees.

Keywords: Quality of work life. Slaughterhouse. Worker's health.

\section{INTRODUÇÃO}

Em função da elevada concorrência, as empresas procuram manterem-se 
competitivas no mercado, porém para alcançar os índices competitivos, necessariamente as empresas buscam produzir com qualidade e produtividade, onde necessitam de trabalhadores que sejam capazes de alcançar os níveis de produtividade, com isso à busca pela qualidade e produtividade tornou-se essencial para as empresas.

As preocupações com a competitividade do mercado criam nas organizações um interesse de redesenhar a natureza de trabalho visando melhorar a produtividade para organização e qualidade de vida para seus trabalhadores (WALTON, 1973).

De acordo com Neto e Alcantara (2013) o bom desempenho de uma organização está diretamente relacionado à obtenção de vantagens competitivas sustentáveis. Segundo Zanardi et al. (2015) para alcançar o sucesso das empresas o fator pessoal tem sido considerado fundamental, pois, sabe-se que um dos meios utilizados para alcançar os níveis estabelecidos de competitividade e produtividade nas empresas é garantir que os trabalhadores tenham qualidade de vida no trabalho, pois é nas mãos dos trabalhadores que passam toda a produção ou produto de uma empresa. Verifica-se que não basta ter trabalhadores treinados e capacitados, locais de trabalho adequados e dentro dos padrões considerados favoráveis para atividade humana, se os trabalhadores não se sentirem satisfeitos e aptos para desempenhar suas atividades.

A busca pela QVT torna-se constante nas organizações, pois a insatisfação com a vida profissional é um fator relevante que se torna um problema que interfere em todas as classes de trabalhadores, o que pode levar a desilusão, com consequências custosas à vida individual e organizacional (WALTON, 1973).

Em geral a QVT prega a valorização do ser humano como trabalhador, na busca pelo equilíbrio entre empresa e trabalhador, por meio das exigências e capacidades (LIMA, 1995). Assim, a QVT passa a ser de responsabilidade tanto da empresa como do trabalhador, da empresa em subsidiar as condições que proporcionem a satisfação dos trabalhadores, e dos trabalhadores em aceitar as condições quando favoráveis. Pois ressalta-se que a QVT não depende somente das empresas, mas também do comportamento dos trabalhadores. 
Para avaliar a QVT em uma organização, há diversos modelos propostos na literatura que oferecem um referencial para a avaliação da satisfação dos trabalhadores, cada um enfatizando determinadas categorias e indicadores. Nesta pesquisa desenvolvida em um abatedouro de frangos foi utilizada uma adaptação do modelo proposto por Richard Walton (1973), que em geral abrange oito (08) dimensões para avaliação dos níveis de qualidade de vida dos trabalhadores (WALTON, 1973).

Outro ponto a ser destacado é que de acordo com a Norma Regulamentadora NR-36 (2015), todo frigorífico e abatedouro de animais deve-se manter condições mínimas que garantam a qualidade de vida no trabalho de seus funcionários (MINISTÉRIO DO TRABALHO E EMREGO NR36, 2015).

Por outro lado diversas pesquisas relacionadas a frigoríficos e abatedouros apresentam dados estatísticos oficiais ligados ao governo que demonstram que nos frigoríficos e abatedouros há um elevado número de casos de doenças e acidentes relacionados ao trabalho, que consecutivamente afeta diretamente a qualidade de vida no trabalho (IBGE, 2015; MARRA, SOUZA, CARDOSO, 2013; MINISTÉRIO DA PREVIDÊNCIA SOCIAL, 2015; OLIVEIRA E MENDES, 2014).

Ressalta-se que nas empresas, uma das funções dos gestores, supervisores e coordenadores é liderar os trabalhadores subordinados a eles, devendo conhecer todos os processos de trabalho e as necessidades dos trabalhadores a fim de atingirem as metas e índices de produtividade e qualidade determinados pela empresa. Sendo assim, são os gestores, supervisores e coordenadores que devem contribuir na garantia de condições propicias de trabalho aos trabalhadores para alcançar o bom resultado dos mesmos e principalmente contribuir na redução de afastamentos devido a doenças e acidentes ocupacionais. Avaliar as condições de QVT torna-se de extrema importância, pois de acordo com Aquino et al. (2012) o trabalho ocupa um espaço importante na vida das pessoas, pois um parte significante do tempo das pessoas é vivenciado dentro das organizações.

Buscando responder à problemática principal, o objetivo desta pesquisa foi avaliar a percepção dos supervisores e gerentes do abatedouro em relação à qualidade de vida no trabalho dos trabalhadores de sua equipe. Tal necessidade foi caracterizada em analisar se conforme a percepção dos trabalhadores a empresa 
atende a um dos requisitos da NR 36 que é garantir a qualidade de vida no trabalho, proporcionando condições que garantam a saúde e integridade física dos trabalhadores.

\section{FUNDAMENTAÇÃO TEÓRICA}

A indústria frigorífica e o complexo de carnes fazem hoje do Brasil um dos principais exportadores mundiais de produtos de origem animal (MARRA, SOUZA, CARDOSO, 2013). Segundo dados do Instituto Brasileiro de Geografia e Estatística - IBGE (2015), o número de frigoríficos vem aumentando constantemente em todo o território nacional, em 2014 os últimos levantamentos a respeito deste cenário identificaram 1.172 empresas do ramo de abate de suínos, aves e de outros pequenos animais (IBGE, 2015).

O aumento do mercado de carnes, inclusive internacional, tem pressionado a chamada competitividade e, nesta perspectiva, as atividades dentro das indústrias são intensificadas na busca de maior produtividade e garantia da qualidade dos alimentos de origem animal, o que pode resultar em fadiga física, mental e psíquica dos trabalhadores, acarretando em doenças ocupacionais e riscos de acidentes (DEFANI, 2007; JAKOBI et al.; 2015; MARRA, SOUZA, CARDOSO, 2013; PEGATIN, 2009; REIS, 2012).

Em relação aos frigoríficos e abatedouros Brasileiros listados conforme a Classificação Nacional de Atividades Econômicas - CNAE, número 1012, foram registrados no último anuário estatístico de acidentes, um total de 10.073 casos de acidentes nas indústrias frigoríficas em todo o território nacional, divididos entre acidentes classificados como típico, trajeto e doença ocupacional (MINISTÉRIO DA PREVIDÊNCIA SOCIAL, 2015).

Os resultados dos anuários estatísticos de frigoríficos apresentam que não apenas o número de empresas e trabalhadores cresce, mas também os números de acidentes e doenças relacionadas ao trabalho nos frigoríficos.

Estimativas nacionais apresentam que 23\% da mão de obra do setor de frigoríficos estão afastadas ou no aguardo de decisões judiciais, em função do adoecimento relacionado ao trabalho (MINISTÉRIO DA PREVIDÊNCIA SOCIAL, 2015). 
Evidentemente não há como mensurar qualidade de vida no trabalho (QVT) desprezando os dados de acidentes e doenças relacionados ao trabalho. As condições de trabalho com as menores exposições a riscos de acidentes e riscos de doenças ocupacionais contribuem diretamente para alcançar índices favoráveis de QVT em uma organização (GRABARSCHI, 2001).

Por outro lado, a busca da QVT não está somente nas empresas em cumprirem sua parte, também depende da postura usual dos trabalhadores. Em grande parte, dependem do próprio indivíduo do valor que atribui à vida, da autoestima e autoimagem, do engajamento profissional, político e social (LIMONGIFRANÇA, 2007). Assim, por mais que as empresas cumpram com seu papel na busca de QVT, isso não irá assegurar a mudança de comportamento das pessoas. Afinal o termo qualidade de vida é complexo devido englobar diversos fatores, que podem ser questões de saúde física, aspectos sociais, culturais, ambientais, psicológicos, entre outros (CASTRO, HOKERBERG, PASSOS, 2013; SEIDL, ZANNON, 2004).

Em função da diversidade de conceituações para a QVT, o termo tem sido considerado um grande desafio para as organizações e estudiosos, há necessidade de aprofundar a revisão da literatura sobre o tema, pois não se pode trabalhar com algo que não se sabe exatamente o que é (FERNANDES, 1996; QUILICI, XAVIER, FRASSON, 2007; TEIXEIRA, et al., 2015). A pesquisa de QVT não é tarefa fácil, em função da diversidade das preferências humanas e diferenças individuais, dos valores pessoais e o grau de importância que cada trabalhador dá a suas necessidades (TEIXEIRA, et al., 2015).

Em geral os modelos de QVT oferecem um referencial para a avaliação da satisfação dos trabalhadores, cada um enfatizando determinadas categorias e indicadores cada qual com sua definição e modelos para avaliação da QVT. Os modelos servem como referencial para implantar um programa de QVT, necessitando ser adaptado para as condições de cada local pesquisado.

\subsection{O modelo de Qualidade de Vida no Trabalho de Richard Walton}


O modelo utilizado na pesquisa identifica que cada uma das categorias de QVT tem suas respectivas variáveis, as quais permitem analisar as principais características da QVT, que pode ser avaliada de acordo com o grau de satisfação dos trabalhadores com os fatores que interferem em seu bem-estar no trabalho, e ainda que novas categorias ou variáveis possam ser geradas, dependendo de aspectos situacionais do ambiente, ou seja, o modelo serve de base para nortear uma pesquisa, podendo ser enriquecido de outros critérios, levando em consideração as peculiaridades da empresa (WALTON, 1973).

O modelo utilizado associa a melhoria da QVT com a performance organizacional, identificando oito critérios que afetam de maneira mais significativa o trabalhador na situação de trabalho (LIMA, 1995; WALTON, 1973). Operacionalmente as oito categorias podem ser definidas da seguinte forma:

1) Compensação justa e adequada: é uma categoria que visa mensurar a QVT em relação à remuneração recebida pelo trabalho. O impulso para ganhar a vida é o emprego, que assim que é alcançada afeta diretamente a QVT. Significa que a adequação da compensação é um conceito relativo, que não existe nenhum consenso sobre normas para avaliar a adequação das indenizações e que a adequação e equidade das remunerações são parcialmente questões ideológicas. Apesar de medidas operacionais aceitas não serem disponíveis para julgar a adequação e a compensação justa do trabalhador, ambos os fatores são determinantes importantes para QVT.

2) Condições de trabalho: visa mensurar a QVT em relação às condições existentes no local de trabalho. Esta variável relaciona-se à importância de condições físicas e horárias para a saúde do trabalhador. Neste sentido, as legislações, uniões, ações e interesses dos trabalhadores têm contribuído para melhores condições de trabalho e que no futuro mais normas serão aplicadas sempre que for necessário melhorar as condições do ambiente de trabalho.

3) Oportunidades para uso e desenvolvimento das capacidades: visa mensurar a QVT em relação às oportunidades que o empregado tem de aplicar, no seu dia-a-dia, seu saber e suas aptidões profissionais. A 
palavra trabalho denota sentidos de desgaste e controle, sendo que tendências de planejamento de trabalho têm progredido em vários postos de trabalho, permitindo que os trabalhadores utilizem e desenvolvam suas competências e conhecimentos.

4) Oportunidades de crescimento e segurança: visa mensurar a QVT em relação às oportunidades que as empresas ou instituições estabelecem para o desenvolvimento e o crescimento pessoal de seus trabalhadores e para a segurança do emprego. Esta variável tem foco nas possibilidades de carreira. Que as promoções em muitas vezes é afastada pelos prérequisitos formais de ensino e que alguns profissionais tende a baixar seus ganhos devido à falta de educação/capacitação continua. Um dos fatores é a falta de interesse por parte dos trabalhadores que deixam de investir em sua carreira e que atenção deve ser dada as aspectos: de desenvolvimento profissional, aplicação de prospectiva, oportunidades avançadas e segurança no emprego.

5) Integração social na organização: visa mensurar a QVT em relação ao grau de integração social existente na empresa ou instituição. Se torna importante dimensão da QVT à natureza de relações pessoais. Se o trabalhador tem identidade satisfatória e experiências, estima-se que será influenciado por atributos na atmosfera do seu local de trabalho.

6) Constitucionalismo na organização: visa mensurar a QVT em relação ao grau em que os direitos do empregado são cumpridos na instituição. Relaciona-se a respeito dos direitos dos trabalhadores, do quanto é afetado pelas decisões que são tomadas pela organização, do interesse dos sindicatos em ajudar os trabalhadores. Aspectos do constitucionalismo são elementos essenciais na prestação de maior QVT.

7) Trabalho e espaço total de vida: visa mensurar a QVT em relação ao equilíbrio entre a vida pessoal do empregado e a vida no trabalho. A experiência individual de trabalho pode ter efeitos negativos ou positivos na vida familiar do trabalhador. Esta experiência individual esta focada na jornada de trabalho, transferências, viagens, ou seja, tudo que não levam ao lazer e tempo com a família. 
8) A relevância social do trabalho na vida: visa mensurar a QVT em relação à percepção do empregado à responsabilidade social da instituição na comunidade, à qualidade de prestação de serviços e ao atendimento aos trabalhadores. Os papéis socialmente benéficos e os efeitos socialmente prejudiciais das organizações empregatícias, afetando a autoestima do trabalhador (WALTON, 1973).

As oito categorias propostas no modelo de qualidade de vida no trabalho utilizado nesta pesquisa, procuram identificar os fatores e dimensões que afetam de maneira mais significativa o trabalhador na situação de trabalho, as categorias incluem questões elementares da situação de trabalho que são importantes para o estudo da QVT (WALTON, 1973).

A escolha do modelo justifica-se pela amplitude das oito categorias de avaliação, as quais enfatizam questões elementares relacionadas às condições internas e externas que podem afetar a qualidade de vida no trabalho.

\section{PROCEDIMENTOS METODOLÓGICOS}

Esta seção tem como objetivo expor o método utilizado para coleta e análise dos dados para realização do estudo. Buscando alcançar os objetivos desta pesquisa, o método utilizado foi caracterizado como exploratório-descritivo (LAKATOS E MARCONI, 2007).

Os resultados foram avaliados de acordo com as oito dimensões gerais adaptadas do modelo de QVT de Walton (1973) e analisado a partir da Análise de Conteúdo proposto por Bardin (2011), com o uso de nuvens de palavras para extração dos principais termos ou palavras citados pelos entrevistados para que se possam fazer inferências relacionadas ao tema principal (BARDIN, 2011; TIMOSSI et al., 2009).

\subsection{Coleta de dados}

Adotando os critérios necessários de amostra, o universo da pesquisa de campo foi 20 trabalhadores que possuem cargo de gestão nas funções de coordenador e supervisor de áreas. Ressalta-se que no total a empresa possui em 
seu quadro funcional 25 profissionais de gestão e que entre os 25 apenas duas são do sexo feminino. Não foi possível realizar a entrevista com as funcionárias do sexo feminino, pois uma estava no período de férias e a outra estava com indisponibilidade de tempo, já os três trabalhadores do sexo masculino que não foram entrevistados, os motivos são que um estava de férias, um estava em compensação de horas e um estava com indisponibilidade de tempo. Ou seja, a pesquisa atendeu $80 \%$ dos cargos sugeridos para entrevista.

Para coleta de dados foi disponibilizada uma sala da empresa, todas as entrevistas foram agendadas previamente com os trabalhadores participantes do estudo. Cada entrevista foi gravada, para posteriormente serem descritas para tabulação dos dados. Para cada entrevista foi agendado o tempo de 20 minutos, sendo que em nenhuma delas o tempo foi ultrapassado. A coleta de dados ocorreu na segunda semana de Outubro de 2015 e todas as entrevistas ocorreram durante a jornada de trabalho dos participantes.

Para coleta dos dados foi utilizado o questionário com 3 perguntas para verificar o perfil dos entrevistados e 8 perguntas de qualidade de vida no trabalho adaptadas do modelo de QVT proposto para o estudo, totalizando em 11 perguntas de entrevista descritas no quadro 1.

Quadro 01 - Questionário de entrevista

Questionário de Entrevista

1) Qual a sua idade?

2) Qual o seu cargo?

3) Sexo: ( ) Masculino ( ) Feminino

Responda as questões considerando como você avalia qual a sua percepção sobre a Qualidade de Vida no Trabalho - QVT de sua equipe em relação a:
4) Remuneração? Por quê?
5) Condição de trabalho? Por quê?
6) Oportunidade para uso e desenvolvimento das capacidades? Por quê?
7) Crescimento e segurança? Por quê?
8) Em relação a integração social na organização, qual a sua percepção de QVT? Por quê?
9) Em relação ao constitucionalismo na organização, qual a sua percepção de QVT? Por quê?
10) Em relação ao trabalho e espaço total de vida, qual a sua percepção de QVT? Por quê?
11) Em relação a relevância social do trabalho na vida, qual a sua percepção de QVT? Por quê?

Fonte: Adaptado de Walton (1973)

Todas as perguntas foram realizadas de forma aberta, no qual foram gravadas as respostas e posteriormente tabuladas para análise do conteúdo. 


\subsection{Análise do Conteúdo}

A partir das respostas das entrevistas, para a análise de conteúdo as frases foram analisadas e os principais termos citados foram tabulados na ferramenta nuvem de palavras, disponível no site: http://www.wordle.net/create. A formatação utilizada na nuvem foi: Fonte: telefotográfico; Layout: bordas retas; horizontal; Cor: preto com branco.

A nuvem de palavras é um recurso gráfico que foi utilizado para apresentar os termos mais frequentes relatados nas entrevistas abertas, auxiliando na análise de conteúdo para comparação dos resultados da pesquisa de QVT.

\subsection{O Modelo de Richard Walton}

Todos os dados das respostas de qualidade de vida no trabalho foram analisados de acordo com a escala do tipo Likert, polarizada em cinco pontos, sendo eles: (1) Muito ruim; (2) Ruim; (3) Nem ruim nem boa; (4) Boa e (5) Ótima.

Para conversão da escala de 1 a 5 para 0 a 100, os valores da escala foram multiplicados pelo número de respostas obtidas de cada item, conforme método adaptado por Timossi et al. (2009) em sua pesquisa.

O método utilizado por Timossi et. al. (2009) é uma adaptação onde os valores 25 e 75 representam pontos de referência para a classificação dos indicadores de QVT, são devidamente caracterizados como insatisfação e satisfação. Assim, os valores externos ao intervalo 25 - 75 tendem para um limite total e inexistente de insatisfação e satisfação, respectivamente. (TIMOSSI et al., 2009; WALTON, 1973).

Os resultados são seccionados em cada intervalo de 25 pontos em quatro segmentos de 6,25 pontos, os valores contidos nestes segmentos podem apresentar as tendências para outra classificação da percepção dos trabalhadores entrevistados (TIMOSSI et al., 2009).

Como referência para avaliação dos resultados foi utilizado à adaptação da Tabela 01, no qual é possível verificar as possíveis classificações de QVT conforme os resultados obtidos nas avaliações (TIMOSSI et al., 2009). 
Tabela 01 - Escala de níveis de satisfação da QVT

\begin{tabular}{|c|c|c|}
\hline Intervalo de pontos & Resultados & Tendência dos resultados \\
\hline 0 a 6,25 & & Tendência para totalmente insatisfatório \\
\hline 6,26 a 18,75 & $\begin{array}{l}\text { Multo } \\
\text { lncaticfatório }\end{array}$ & Tendência neutra \\
\hline 18,76 a 25 & Insatıstatorio & Tendência para insatisfatório \\
\hline 25,01 a 31,25 & & Tendência para muito insatisfatório \\
\hline 31,26 a 43,75 & Insatisfatório & Tendência neutra \\
\hline 43,76 a 50 & & Tendência para neutro/satisfatório \\
\hline 50,01 a 56,25 & & Tendência para neutro/insatisfatório \\
\hline 56,26 a 68,75 & Satisfatório & Tendência neutra \\
\hline 68,76 a 75 & & Tendência para muito satisfatório \\
\hline 75,01 a 81,25 & & Tendência para satisfatório \\
\hline 81,26 a 93,75 & Soticfatórin & Tendência neutra \\
\hline 93,76 a 100 & Sallstatorio & Tendência para totalmente satisfatório \\
\hline
\end{tabular}

Fonte: Adaptado por Timossi et. al. (2009)

Os resultados foram analisados conforme os intervalos para classificar a percepção dos trabalhadores, pois quantificar algo subjetivo é possível com a construção de um modelo racional de pensamento (TIMOSSI et al., 2009).

Os resultados foram analisados por questão, fazendo-se cruzamento da análise de conteúdo para fundamentar o nível de satisfação de QVT de cada item avaliado.

A pesquisa foi aprovada pelo Comitê de Ética e Pesquisa da Universidade Federal de Santa Catarina (UFSC) em 15 de setembro de 2015, sob o número 47373215.5.0000.0121 e houve consentimento da empresa em realizar a pesquisa. A pesquisa atende a Resolução CNS0020466/12, de 12/09/2012 e complementares.

\section{RESULTADOS}

\subsection{Perfil dos trabalhadores entrevistados}

Os trabalhadores participantes da pesquisa detêm as seguintes características sócio demográficas: quanto à função, 65\% possuem cargo de supervisor de área e 35\% possuem o cargo de coordenador de área. Quanto ao sexo, 100\% masculino. Em relação a faixa etária, 35\% se encontram na idade de 21 a 30 anos, 45\% se encontram na idade de 31 a 40 anos e 20\% se encontram na idade de 41 a 50 anos. Com relação ao tempo de trabalho na empresa, do total dos participantes, 35\% estão entre 3 e 5 anos, 25\% entre 1 e 3 anos, 20\% maior que 10 
anos, 15\% entre 5 e 10 anos e 5\% com menos de um ano de empresa. O estado civil dos participantes do estudo é $65 \%$ casados, $25 \%$ solteiro e $10 \%$ outra situação.

Em síntese, os perfis dos trabalhadores entrevistados é que foi predominante do sexo masculino com faixa de idade entre 31 e 40 anos, 65\% casados, 60\% estão entre 1 e 5 anos de empresa.

\subsection{Avaliações de qualidade de vida no trabalho conforme percepção dos entrevistados}

A seguir apresentam-se a Tabela 02 com os resultados da pesquisa elaborada conforme critérios adaptados do modelo de qualidade de vida no trabalho QVT (WALTON 1973). Na Tabela 02 estão representados as respostas da entrevista e os resultados pontuados da percepção dos trabalhadores entrevistados em relação condição de qualidade de vida dos trabalhadores subordinados. Conforme descrito na metodologia todos os resultados foram avaliados utilizando o cálculo de escore das respostas conforme modelo adaptado e validado por Timossi et. al. (2009).

Tabela 02 - Resultados dos níveis de satisfação da QVT

\begin{tabular}{|c|c|c|c|c|c|c|}
\hline Indicadores & $\begin{array}{l}\text { Muito } \\
\text { Ruim }\end{array}$ & Ruim & $\begin{array}{c}\text { Nem } \\
\text { Ruim } \\
\text { nem Boa }\end{array}$ & Boa & Ótima & $\begin{array}{l}\text { Escore } \\
\text { calculado }\end{array}$ \\
\hline Respostas Questão 4 & 0 & 7 & 4 & 9 & 0 & \multirow{2}{*}{62} \\
\hline Pontos Questão 4 & 0 & 14 & 12 & 36 & 0 & \\
\hline Respostas Questão 5 & 0 & 6 & 4 & 9 & 1 & \multirow{2}{*}{65} \\
\hline Pontos Questão 5 & 0 & 12 & 12 & 36 & 5 & \\
\hline Respostas Questão 6 & 0 & 6 & 4 & 8 & 2 & \multirow{2}{*}{66} \\
\hline Pontos Questão 6 & 0 & 12 & 12 & 32 & 10 & \\
\hline Respostas Questão 7 & 0 & 1 & 0 & 6 & 13 & \multirow{2}{*}{91} \\
\hline Pontos Questão 7 & 0 & 2 & 0 & 24 & 65 & \\
\hline Respostas Questão 8 & 0 & 3 & 1 & 11 & 5 & \multirow{2}{*}{78} \\
\hline Pontos Questão 8 & 0 & 6 & 3 & 44 & 25 & \\
\hline Respostas Questão 9 & 0 & 6 & 1 & 12 & 1 & \multirow{2}{*}{68} \\
\hline Pontos Questão 9 & 0 & 12 & 3 & 48 & 5 & \\
\hline Respostas Questão 10 & 0 & 8 & 8 & 4 & 0 & \multirow{2}{*}{56} \\
\hline Pontos Questão 10 & 0 & 16 & 24 & 16 & 0 & \\
\hline Respostas Questão 11 & 0 & 8 & 0 & 9 & 3 & \multirow{2}{*}{67} \\
\hline Pontos Questão 11 & 0 & 16 & 0 & 36 & 15 & \\
\hline
\end{tabular}

Fonte: Dados da pesquisa (2015) 
É possível verificar na Tabela 02 os resultados das questões, as pontuações e os valores dos escores calculados dos resultados da análise das questões. Para melhor visualizar, os dados foram apresentados na Figura 01 com os escores calculados dos resultados de cada questão de QVT e sua classificação nos níveis de satisfação conforme proposto na metodologia deste estudo.

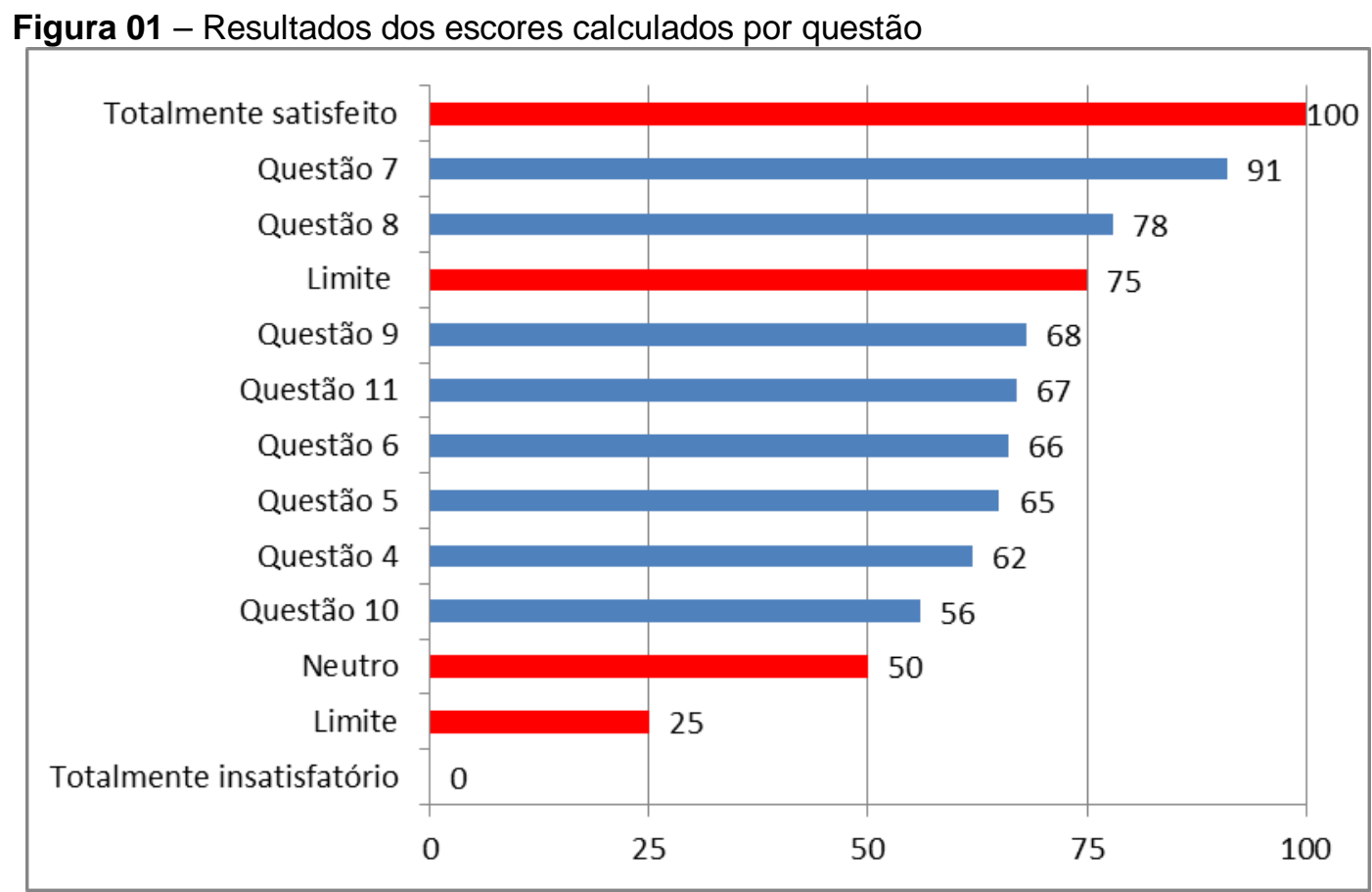

Fonte: Dados da pesquisa (2015)

Verifica-se na Figura 01 que nenhuma das questões ficou abaixo do valor neutro com 50 pontos, ou seja, não houve questões enquadradas como insatisfatória e totalmente insatisfatória. Por outro lado, entre 50 pontos e 75 pontos, área classificada como satisfatória, obteve-se resultados calculados neste intervalo as questões de número $4,5,6,9,10$ e 11 , e na condição de totalmente satisfatória obteve-se enquadramento das questões 7 e 8.

Ressalta-se que é possível verificar comparando com o modelo proposto conforme o escore calculado em qual tendência a variável de QVT pode ser classificada. Os resultados com suas possíveis tendências são apresentados comparando com a análise dos resultados da nuvem de palavras apresentada na Figura 02. 
A Figura 02 apresenta as nuvens de palavras dos textos tabulados de cada questão de QVT, o canto inferior direito de cada nuvem é representado o número da questão que ela representa.

Figura 02 - Nuvem de palavras das respostas de QVT

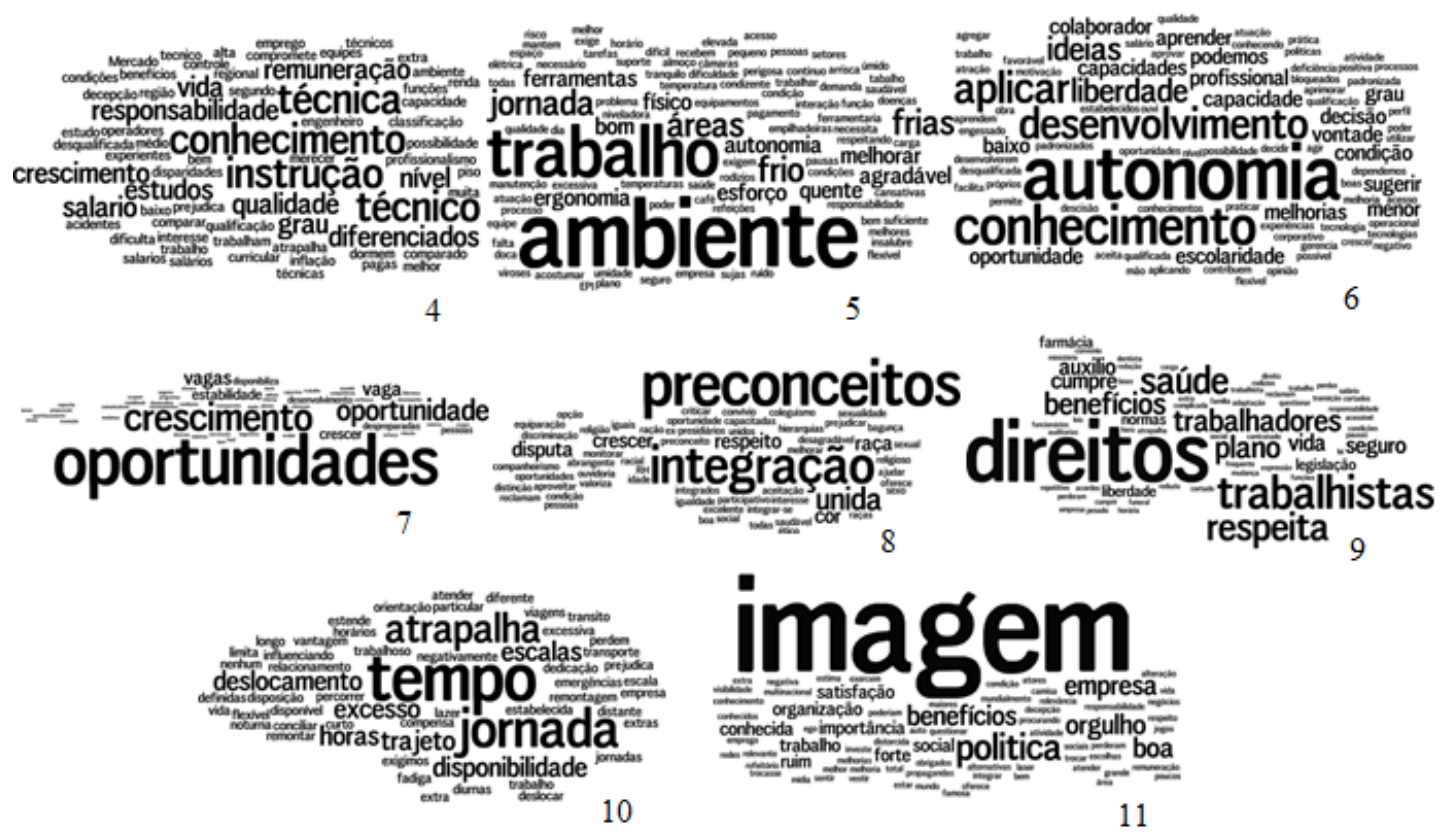

Fonte: Dados da pesquisa (2015)

Seguindo a ordem sequencial das questões de QVT, a primeira questão a ser discutida é a de número 4 referente à Remuneração, classificada com escore de 62 pontos, como satisfatória com tendência neutra, verifica-se na nuvem de palavras que o destaque nas respostas foi para questões sobre: técnico (a), conhecimento e instrução.

Como referência cita-se uma das respostas obtidas referente à questão:

"Considero boa devido a remuneração deles ser compatível com a função por conta seja do conhecimento ou da instrução técnica e eles sabem que eles tem possibilidade de crescimento salarial dentro da própria função, mas para isso eles precisam especializar-se mais".

Verifica-se que a condição é considerada satisfatória em função do ganho proporcionado a eles devido ao seu grau de instrução e conhecimento técnico. Fica evidente que para melhorar este item os trabalhadores necessitam aperfeiçoar-se para ocupar novas oportunidades na empresa.

Com relação à questão de número 5 referente à condição de trabalho foi 
classificada com escore de 65 pontos, como satisfatória com tendência neutra e com destaque na nuvem de palavras para: ambiente, trabalho, frio, jornada, áreas e frias. Como referência cita-se uma das respostas:

"Também considero boa, porém temos um problema devido à dificuldade do pessoal se acostumar no setor devido ao frio, então no início é bem difícil para todos colaboradores, está é uma condição que dificulta a permanência de algumas pessoas na empresa devido às condições de trabalho".

Percebe-se que a condição foi classificada no geral como boa, porém se analisada em função da temperatura dos ambientes de trabalho relatadas na maioria das respostas, dificulta a elevação do nível de satisfação dos trabalhadores em relação às condições de trabalho, haja vista que as temperaturas de diversos setores do frigorífico são controladas para manter-se nos níveis para atender as legislações do Sistema Federal de Inspeção SIF. Outros fatores também foram evidenciados na nuvem de palavras tais como ergonomia, ferramentas, esforço, no qual todos estes são possíveis de tomar ações pontuais nas causas, porém atenderiam condições específicas que no geral não atenderiam o maior número de trabalhadores.

A questão de número 6 referente à oportunidade para uso e desenvolvimento das capacidades, classificada como satisfatória com tendência neutra, com escore de 66 pontos, obteve como destaque na nuvem de palavras: autonomia, conhecimento, desenvolvimento e aplicar. Como referência cita-se a seguinte resposta:

"É bom o desenvolvimento deles. Por que a gente tem uma autonomia grande em toda equipe, eles têm uma boa autonomia para agir dentro de toda unidade aplicando suas capacidades".

Em geral verifica-se que segundo os coordenados e supervisores, que seus subordinados têm autonomia para desenvolver suas capacidades, no qual seus conhecimentos podem ser aplicados quando considerados bons para o processo produtivo. Este item do modelo de QVT utilizado pode melhorar o conceito de satisfação para um nível de ótimo em conjunto com a questão de número 4 sobre remuneração no qual refere-se que quanto mais capacitado tiver o trabalhador, maiores são as oportunidades de aplicar e desenvolver essas capacidades no dia-adia de trabalho, haja vista que há evidências de não existir restrições por parte da empresa a este item avaliado. 
Com relação à questão de número 7 referente ao crescimento e segurança foi a maior classificação com escore de 91 pontos, como muito satisfatória com tendência neutra e com destaque na nuvem de palavras para: oportunidades e crescimento. Como referência cita-se uma das respostas:

"Ótimo. Por que a empresa disponibiliza diversas oportunidades de
crescimento, eles visualizam isso através de editais, de comunicativos, eles
tem várias oportunidades de cargos e mostra o que precisa para que o
colaborador alcance esse objetivo e a empresa tem o programa de novos
talentos interna no qual busca visualizar os talentos internos para capacitar
para trabalhar no administrativo ou supervisor na indústria".

Verifica-se que os coordenadores e supervisores relataram que a questão de crescimento e segurança na empresa é muito positiva com relação à qualidade de vida, atribuem esta condição ao elevado número de oportunidades de vagas que a empresa disponibiliza para todos os trabalhadores, porém um item evidenciado em algumas respostas é que a maioria destas vagas é para áreas administrativas e de supervisão, no qual exige níveis de escolaridade superiores ao da maioria dos trabalhadores das linhas de produção. Novamente existe uma relação com a questão 4 anteriormente discutida, que ficou evidente a questão da capacitação profissional dos trabalhadores.

A questão de número 8 referente a integração social na organização, classificada com escore de 78 pontos, como muito satisfatória com tendência para satisfatória, obteve como destaque na nuvem de palavras: integração, preconceitos e unida. Como referência cita-se a seguinte resposta:

"Bom. Por que não há preconceitos e vejo que a equipe é bem unida e a empresa oferece canais de ouvidoria e existe um $\mathrm{RH}$ bem participativo na empresa".

Em geral é um item de QVT que obteve um resultado classificado como muito satisfatório, a maioria dos entrevistados atribuíram a boa relação que existe entre os trabalhadores de suas equipes. Como é um item que tem tendência a baixar no nível de satisfação as ações devem priorizar melhorias para manter o nível considerado como muito satisfatório.

Com relação à questão de número 9 referente a constitucionalismo na organização foi classificada com escore de 68 pontos, como satisfatória com 
tendência neutra e com destaque na nuvem de palavras para: direitos trabalhistas, respeita e saúde. Como referência cita-se uma das respostas:

"Isso é bom. A empresa sempre demonstra ações que respeita os direitos dos colaboradores, não temos atitude de que uma ação ou outra mesmo que isolada afeta os direitos dos trabalhadores. A empresa segue totalmente os direitos que os trabalhadores têm".

Em geral os coordenadores e supervisores atribuem que a condição é boa devido ao respeito pelos direitos dos trabalhadores que existe na organização. Por outro lado nesta questão houve um destaque para palavra saúde que foi atribuída a questão de mudanças que ocorreram recentemente no plano de saúde, farmácia e seguro de vida, em função de uma transição de venda da empresa antiga para um novo grupo, os relatos são em geral que houve certa insatisfação em relação às mudanças. Esta mudança pode gerar uma tendência do item avaliado para insatisfação se ações não forem realizadas, porém foi possível verificar nos relatos que esta questão com o decorrer do tempo, como esta é uma condição obrigatória da empresa, novos trabalhadores contratados podem não relevar este item como insatisfatório devido não ter utilizado planos anteriores.

Com relação à questão de número 10 referente a trabalho e espaço total de vida, esta foi classificada com o menor escore de 56 pontos, como satisfatória com tendência para neutro e insatisfatório e com destaque na nuvem de palavras para: tempo, jornada, atrapalha, escalas, deslocamento, horas, excesso, trajeto e disponibilidade. Como referência cita-se uma das respostas:

"Regular por que os nossos trabalhadores estão num "raio" distante da empresa no qual eles perdem tempo no transporte, em torno de 45 minutos a 02 horas para percorrer o trajeto entre empresa e casa, isso atrapalha na qualidade de vida deles com suas famílias".

Os coordenadores e supervisores enfatizaram que este item atende as condições, porém existem falhas que devem ser reavaliadas pelos responsáveis da empresa. Eles identificam certa insatisfação na questão do tempo de deslocamento que os trabalhadores fazem para fazer o trajeto casa/empresa e vice-versa, como a maioria utiliza transporte fretado, este apresentou algumas falhas de logística relatadas nas entrevistas. As condições de tempo de trajeto, jornada de 08h:48min diária na empresa e algumas escalas de finais de semana, que ocorrem devido as 
programações de abate em finais de semana, os supervisores queixam-se da disponibilidade que seus subordinados devem ter para com a empresa. Enfim, a questão foi classificada como satisfatória, porém com tendência a insatisfação no qual realmente pode ser o sentimento dos trabalhadores devido à condição do trabalho e disponibilidade para o espaço de vida fora do trabalho.

Com relação à questão de número 11 referente a relevância social do trabalho na vida, foi classificada com escore de 67 pontos, como satisfatória com tendência para neutro e com destaque na nuvem de palavras para: imagem, politica, benefícios, orgulho, empresa e boa. Como referência cita-se uma das respostas:

"Boa. Todos têm uma imagem muito boa da empresa, de respeito e responsabilidade e o pessoal se sente com orgulho, a imagem é muito boa".

De acordo com os entrevistados, em geral este item atende as condições e os trabalhadores sentem orgulho da imagem da empresa perante a sociedade e que para eles a política de trabalho da empresa é compatível com a realidade de trabalho. Evidentemente pode-se melhorar este indicador em geral, para alguns dos entrevistados, a empresa não investe o suficiente em propagandas das melhorias internas.

\section{DISCUSSÃO DOS RESULTADOS}

Em geral a média referente às oito questões de qualidade de vida obteve-se um escore calculado de 69 pontos, com classificação geral satisfatória tendendo ao muito satisfatório. Ressalta-se que os escores devem ser avaliados para ações de forma isolada por cada questão.

O maior escore calculado foi 91 pontos para a questão sobre crescimento e segurança, porém verifica-se que na questão sobre a remuneração com escore de 62 pontos que há uma condição que pode afetar o requisito da questão crescimento e segurança.

Em geral na questão remuneração os respondentes relatam que poderia melhorar se houvesse maior conhecimento técnico dos trabalhadores de suas equipes e que em contra partida na questão crescimento e segurança verifica-se 
que há oportunidades e que essas oportunidades para crescimento estão direcionadas a cargos específicos que demandam mão de obra qualificada.

Pode-se confirmar esta condição também evidenciada em outras pesquisas onde citam que os frigoríficos necessitam de pessoas mais qualificadas, treinadas e com disponibilidade de flexibilização para atuar na empresa e que a qualificação torna-se um importante atributo para a inserção e a permanência dos trabalhadores de frigoríficos (OLIVEIRA E MENDES, 2014).

Com relação ao menor escore calculado de 56 pontos para o trabalho e espaço total de vida este deve ser o item em que as ações devem ser iniciadas para melhorar o escore aproximando da média calculada. Nota-se neste item que o foco foi à questão do tempo de disponibilidade no qual está sendo influenciado diretamente em relação ao tempo de ida e volta para empresa, com casos de tempo de 4 horas totais entre ida e volta, no qual se contabilizar com a jornada obrigatória de trabalho de 08h:48min, dá um tempo total de disponibilidade de 12h:48min, evidentemente reduzindo o tempo para os espaço de vida fora do trabalho. A condição de disponibilidade também foi evidenciada em outras pesquisas como marcante para a permanência de trabalhadores de frigoríficos (OLIVEIRA E MENDES, 2014).

\section{CONSIDERAÇÕES FINAIS}

Primeiramente pode-se concluir que o objetivo da pesquisa que foi avaliar a percepção dos gestores das equipes do abatedouro em relação à qualidade de vida no trabalho dos operários de sua equipe foi alcançado.

Como a pesquisa foi realizada com trabalhadores de um abatedouro de frangos e um dos objetivos da Norma Regulamentadora NR-36 (2015), norma específica para frigoríficos e abatedouros é que todo frigorífico e abatedouro de animais devem manter condições mínimas que garantam a qualidade de vida no trabalho (MINISTÉRIO DO TRABALHO E EMREGO NR36, 2015). Quanto a este item pode se concluir que com uma média geral de 69 pontos em função do modelo adaptado de qualidade de vida no trabalho, os resultados apontam que a percepção dos coordenadores e supervisores é que as condições do abatedouro atende às 
condições mínimas de QVT. Como a NR-36 não especifica qual o meio de mensurar as condições de qualidade de vida no trabalho e quais os requisitos devem ser avaliados, pode-se concluir que neste item a empresa avaliada atende a este objetivo parcialmente.

É de suma importância ressaltar que com os resultados desta pesquisa podem-se direcionar esforços por parte da empresa para verificar quais os requisitos de QVT que devem ser iniciadas ações para melhoria da condição de QVT geral e condições que impactam diretamente na saúde e integridade física dos trabalhadores. No estudo nota-se que o item que deve ser primeiramente investigado para propor ações é a questão do trabalho e espaço total de vida, em função do resultado com menor escore calculado. Este item pode impactar diretamente na saúde do trabalhador, pois conforme os resultados o tempo de disponibilidade para a empresa é elevado e restringe muito o tempo para descanso e lazer, dificultando a condição de realização de atividades externas que podem contribuir na saúde do trabalhador.

Outra condição evidenciada com os resultados da pesquisa foi o item que é totalmente satisfatório por parte da empresa e que não é em alguns casos acessíveis a todos os trabalhadores, tornando necessário que seja reavaliado, está condição ficou evidente na questão sobre crescimento e segurança no qual a empresa dispõe conforme relatos de diversas oportunidades de vagas no qual existe a possibilidade de crescimento e que em contra partida na questão sobre remuneração ficou evidente que para os trabalhadores alcançarem uma remuneração mais adequada deve investir em capacitação técnica.

Com relação ao modelo de avaliação proposto por Timossi et al. (2009) foi possível verificar o nível de satisfação da QVT e sua possível tendência em relação a sua classificação assim como verificar condições que podem afetar a saúde e integridade física dos trabalhadores. Os resultados apontam apenas duas tendências fora da condição neutra, sendo uma positiva e uma negativa, sendo a negativa com tendência para o insatisfatório à questão do trabalho e espaço total de vida. Com relação à nuvem de palavras para todas as respostas os conceitos analisados foram relevantes para explicar os fatores que afetam de uma forma positiva e negativa as condições de QVT dos trabalhadores. 
Por fim, verifica-se que o modelo utilizado nessa pesquisa possibilita mensurar as necessidades da empresa no nível gerencial para garantir condições propicias de QVT. Para pesquisas futuras recomenda-se avaliar a percepção dos trabalhadores dos cargos supervisionados pelos gestores, utilizar todos os subitens do questionário de Walton, aplicar o questionário em outros gestores de outros frigoríficos, assim como comparar os resultados obtidos com resultados de QVT no mesmo modelo de atividade em outros países.

\section{REFERÊNCIAS}

AQUINO, D.S., et al. Análise da qualidade de vida no trabalho no setor de costura em uma indústria de confecção. Revista Po: R. Eletr. de Eng. de Produção e Correlatas, [s.l.], v. 12, n. 3, p. 585-603, jul/set. 2012. Associação Brasileira de Engenharia de Produção ABEPRO. http://dx.doi.org/10.14488/1676-1901.v12i3.871

BARDIN, L. Análise de conteúdo. São Paulo: Edições 70, 2011, 229 p.

CASTRO, M.M.L.D.; HOKERBERG, Y.H.M.; PASSOS S.R.L. Validade dimensional do instrumento de qualidade de vida WHOQOL-BREF aplicado a trabalhadores de saúde. Cad. Saúde Pública, Rio de Janeiro, 29 (7):1357-1369, jul, 2013.

DEFANI, J. C. Avaliação do perfil antropométrico e análise dinamométrica dos trabalhadores da agroindústria do setor de frigoríficos e abatedouros: O Caso da Perdigão - Carambeí. 2007. 143 f. Dissertação (Mestrado) - Curso de Pós Graduação em Engenharia de Produção, Programa de Pós Graduação em Engenharia de Produção, Universidade Tecnológica Federal do Paraná, Ponta Grossa, 2007.

FEINBERG, Jonathan. Wordle beuriful word clouds. Disponível em: $<$ http://www.wordle.net/>. Acesso em: 10 out. 2015.

FERNANDES, E.C. Qualidade de vida no trabalho: como medir para melhorar. Salvador, BA: Casa da Qualidade, 1996.

GRABARSCHI I, V.S.S. Qualidade de vida no trabalho e sua influência na percepção da qualidade dos serviços: estudo de caso em instituição de nível superior. $2001.115 \mathrm{f}$. Dissertação (Mestrado) - Curso de Engenharia de Produção, Centro Tecnológico, Universidade Federal de Santa Catarina, Florianópolis, 2012. Disponível em: <http://ppgep.ufsc.br/>. Acesso em: 18 Out. 2015.

INSTITUTO BRASILEIRO DE GEOGRAFIA E ESTATÍSTICA. Base de dados agregados (SIDRA) Pesquisa Trimestral do Abate de Animais (2013). Disponível em: $<$ http://www.sidra.ibge.gov.br/bda/tabela/listabl.asp?c=1093\&z=t\&o=24>. Acesso em: 04 out. 2015.

JAKOBI, H.R. et al. Benefícios auxílio-doença concedidos aos trabalhadores empregados no ramo de carne e pescado no Brasil em 2008. Cad. Saúde Pública, Rio de Janeiro, 31(1): 194-207, jan, 2015. 
LAKATOS, E. M.; MARCONI, M. A. Técnicas de pesquisa. São Paulo: Atlas, 2007.

LIMA, I.S. Qualidade de vida no trabalho na construção de edificações: avaliação do nível de satisfação dos operários de empresas de pequeno porte. 1995. 215 f. Tese (Doutorado) - Curso de Engenharia de Produção, Centro Tecnológico, Universidade Federal de Santa Catarina, Florianópolis, 1995. Disponível em: <http://ppgep.ufsc.br/>. Acesso em: 10 out. 2015.

LIMONGI-FRANÇA, A.C. Qualidade de vida no trabalho - QVT: Conceitos e práticas nas Empresa da Sociedade Pós-industrial. São Paulo: Atlas, 2007.

QUILICI RFM, Xavier AAP, Frasson AC. Mudanças Organizacionais Promovendo um Aumento na Produtividade Através da Qualidade de Vida no Trabalho (QVT) em uma Empresa Estocadora de Soja: Satisfação/Motivação: Estudo de Caso. In: Encontro Nacional de Engenharia de Produção, XXVII ENEGEP, 2007. Anais... Foz do Iguaçu, 2007.

MARRA, G. C.; SOUZA, L. H.; CARDOSO, T. A. O. Biossegurança no trabalho em frigoríficos: da margem do lucro à margem da segurança. Ciênc. saúde coletiva [online]. 2013, vol.18, n.11, p. 3259-3271. ISSN 1413-8123.

MINISTÉRIO DA PREVIDÊNCIA SOCIAL. Anuário estatístico de acidentes de trabalho AEAT Infologo (base de dados históricos de acidentes de trabalho). Disponível em: <http://www3.dataprev.gov.br/aeat/> Acesso em: 15 out. 2015.

MINISTÉRIO DO TRABALHO E EMPREGO. NR 36: Segurança e Saúde no Trabalho em Empresas de Abate e Processamento de Carnes e Derivados. Brasil, 2015. 19 p. Disponível em:<http://portal.mte.gov.br/data/files/8A7C812D3DCADFC3013E237DCD6635C2/NR-36 (atualizada 2013).pdf>. Acesso em: 20 out. 2015.

NETO, J.S.; ALCANTARA, R.L.C. Competências essenciais presentes em frigoríficos brasileiros exportadores para a Europa: Um estudo multicaso. Revista Po: R. Eletr. de Eng. de Produção e Correlatas, [s.l.], v. 13, n. 1, p. 180-207, jan/mar. 2013. Associação Brasileira de Engenharia de Produção - ABEPRO. http://dx.doi.org/10.14488/16761901.v13i1.1107

OLIVEIRA, P.A.B.; MENDES, J.M.R. Processo de trabalho e condições de trabalho em frigoríficos de aves: relato de uma experiência de vigilância em saúde do trabalhador. Ciênc. saúde coletiva [online]. 2014, vol.19, n.12, p. 4627-4635. ISSN 1413-8123.

PEGATIN, T. O. Estratégia para análise de efeitos dos curtos tempos de ciclo na funcionalidade de membros superiores em trabalhadores de atividades semiautomatizadas. 2009. 104 f. Dissertação (Mestrado) - Curso de Engenharia de Produção, Departamento de Pós Graduação em Engenharia de Produção, Universidade Tecnológica Federal do Paraná, Ponta Grossa, 2009. Disponível em: <http://www.pg.utfpr.edu.br>. Acesso em: 05 nov. 2015.

REIS, P. F. O trabalho repetitivo em frigorífico: utilização da estesiometria da mão como proposta para avaliação dos níveis de LER/DORT nas síndromes compressivas dos membros superiores. 2012. 181 f. Tese (Doutorado) - Curso de Engenharia de Produção, Centro Tecnológico, Universidade Federal de Santa Catarina, Florianópolis, 2012. Disponível em: <http://ppgep.ufsc.br/>. Acesso em: 08 nov. 2015. 
SEIDL, E.M.F.; ZANNON, C.M.L.C. Qualidade de vida e saúde: aspectos conceituais e metodológicos. Cad. Saúde Pública, Rio de Janeiro. 2004, vol. 20, n. 2, p. 580-588.

TEIXEIRA, J.R.B. et al. Associação entre aspectos psicossociais do trabalho e qualidade de vida de mototaxistas. Cad. Saúde Pública, Rio de Janeiro. 2015, vol. 31 n.1, p. 97-110.

TIMOSSI, L.S. et al. Adaptação do modelo de Walton para avaliação da Qualidade de Vida no Trabalho. Revista da Educação Física, Maringá. 2009, vol. 20, n.3, p. 395-405.

WALTON, R.E. Quality of Working Life: What Is It? Sloan Management Review, Cambridge.1973, vol. 15, n. 1, p. 11-21.

ZANARDI et al. Correlações entre qualidade de vida no trabalho e comprometimento organizacional: Estudo em uma unidade de varejo de vestuário na cidade de Joinville/SC. Revista Po: R. Eletr. de Eng. de Produção e Correlatas, [s.I.], v. 15, n. 2, p. 573-600, abr/jun. 2015. Associação Brasileira de Engenharia de Produção - ABEPRO. http://dx.doi.org/10.14488/1676-1901.v15i2.1928

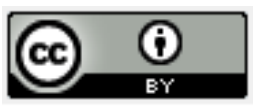

Artigo recebido em 27/01/2016 e aceito para publicação em 06/04/2017 DOI: http://dx.doi.org/10.14488/1676-1901.v17i2.2372 